\title{
Profiling lower extremity injuries sustained in a state police population: a retrospective cohort study
}

\author{
Kate Lyons ${ }^{1}$, Mick Stierli ${ }^{2}$, Ben Hinton ${ }^{2}$, Rodney Pope ${ }^{3,4}$ and Robin Orr ${ }^{13^{*}}$ (D)
}

\begin{abstract}
Background: Tactical populations, such as military, firefighter and law enforcement populations, are known to suffer a relatively high number of musculoskeletal injuries, with the lower extremity of notable concern. The aim of this retrospective cohort study was to determine the profile of lower extremity musculoskeletal injuries within a state police agency.

Methods: Injury data were collected by an Australian state police force over a 7-year period (2009-2016) and records not meeting the definition for lower extremity musculoskeletal injury were excluded. Statistical analyses were descriptive, with frequencies, means and standard deviations calculated where applicable. Chi-square analysis was performed to compare injury profiles by gender. Ethics approval was granted by Bond University Human Research Ethics Committee (Research Protocol 15360).
\end{abstract}

Results: Of the initial 65,579 incident records, 12,452 (19\%) related to lower extremity musculoskeletal injuries. The knee was the most commonly injured site (31.4\%) with sprains/strains (42.3\%) the most common nature of injury and arresting offenders (24.2\%) the most common activity at time of injury. Slips/trips/falls (37.8\%) was found to be the most common cause of injury. Variations were found between genders, most notably within the injury activity $(p<.001) .27 .1 \%$ of male officers were injured when arresting offenders compared to $16.5 \%$ for female officers. Walking/running contributed to $17.9 \%$ of female officer incidents compared to $9.3 \%$ for male officers. The mean number of hours worked prior to injury occurrence was $6.00 \pm 3.56 \mathrm{~h}$ with significantly more injuries occurring in the middle third of the shift $(4.34-8.67 \mathrm{~h}, p<0.001)$.

Conclusions: While the proportion of injuries that affected the lower extremity was lower for police, the leading sites of injuries (knees and ankles) were similar to those of military and fire and rescue populations. Variations between genders suggest there may need to be differences in return-to-work rehabilitation.

Keywords: Law enforcement, Police, Injuries, Lower extremity, Musculoskeletal

\footnotetext{
* Correspondence: rorr@bond.edu.au

'Bond Institute of Health and Sport, Bond University, Gold Coast, QLD 4229,

Australia

${ }^{3}$ Tactical Research Unit, Bond University, Gold Coast, QLD 4229, Australia

Full list of author information is available at the end of the article
}

(c) The Author(s). 2021 Open Access This article is licensed under a Creative Commons Attribution 4.0 International License, which permits use, sharing, adaptation, distribution and reproduction in any medium or format, as long as you give appropriate credit to the original author(s) and the source, provide a link to the Creative Commons licence, and indicate if changes were made. The images or other third party material in this article are included in the article's Creative Commons licence, unless indicated otherwise in a credit line to the material. If material is not included in the article's Creative Commons licence and your intended use is not permitted by statutory regulation or exceeds the permitted use, you will need to obtain permission directly from the copyright holder. To view a copy of this licence, visit http://creativecommons.org/licenses/by/4.0/ The Creative Commons Public Domain Dedication waiver (http://creativecommons.org/publicdomain/zero/1.0/) applies to the data made available in this article, unless otherwise stated in a credit line to the data. 


\section{Background}

The Centre for Disease Control and Prevention defines musculoskeletal (MSK) injuries as soft-tissue injuries affecting the muscles, nerves, tendons, joints and cartilage, caused by repetitive motions either sudden or sustained, external forces, awkward positions, or vibrations [1]. In the literature, MSK injuries have also been defined as any injury to a joint, ligament, tendon, bone or muscle [2]. MSK disorders or injuries are common in occupational settings [3-5]. Tactical populations, such as military (inclusive of Army, Navy and Airforce), firefighter (inclusive of fire and rescue) and law enforcement (inclusive of police and custodial) populations, are known to suffer a relatively high number of MSK injuries [6-9]. For example, MSK injuries, to the lower extremity alone, have been reported to make up between $32 \%$ [6] and 43\% [9] of injuries within military populations in Australia and New Zealand respectively. In Australian fire and rescue personnel, MSK injuries were found to contribute $66.5 \%$ of all injuries [7]. Among these injuries, the knee and ankle were the most commonly injured body sites [7]. In Australian law enforcement populations detailed MSK injury data is limited. However, Australia law enforcement injuries, in general, have been reported to occur at a rate of 3023 injuries per 100,000 officers [10]. More recently, an audit of work hours lost due to injury reported an average of 78 lost hours per officer during 2018-19, up 14 lost hours per officer from the preceding year [11]. Noting that most literature reports incidence rates of injuries without identifying the proportions of those injuries that are MSK injuries [1, 12-18], it is not surprising that it has been reported that there is insufficient research and data relating to occupational injuries affecting law enforcement officers (LEO) [19].

One known cause of MSK injuries associated with tactical professions is load carriage [6, 9, 20-23]. Like military personnel and fire fighters, LEO are required to wear and carry loads $[24,25]$, which can range from $3 \mathrm{~kg}$ to $15 \mathrm{~kg}$ [26] in general duties officers, and from $22 \mathrm{~kg}$ [27] to $40 \mathrm{~kg}$ [28] in specialist officers (e.g. riot squad officers, special weapons and tactics teams, etc.). Typically these loads, which consists of body armour, duty belts, baton, sidearm, handcuffs, etc. [25], are worn by LEO when they are conducting manual handling tasks, undertaking offensive or self-defence manoeuvres while arresting suspects or noncompliant offenders, or undertaking foot pursuits of suspects $[28,29]$. In addition, LEO can be required to perform these tasks, whilst wearing these loads, in variable situations that are arduous, unpredictable and can be life threatening in some circumstances [30]. Physical stress, including that from load carriage, heavy lifting, awkward positioning and environmental stressors, has been shown to increase the risk of sustaining an occupational injury [31]. On this basis, it is not surprising that LEO have a higher MSK injury risk when compared to the general population [12].
MSK injuries in the law enforcement work force can have considerable downstream effects, beyond lost productivity. For example, while studies have demonstrated that productivity, in terms of quality/quantity of work and presenteeism, can be adversely impacted by MSK injury [32, 33], loss of personnel due to MSK injuries, particularly those leading to long term or permanent disability, can require backfilling of positions, the recruitment and training of new personnel, and an increased occupational workload for remaining staff members [33]. For LEOs this could also mean increases in overtime to cover for those who are injured and therefore greater exposure of personnel to occupational risk factors.

Despite the high risks of injury to LEO and the potential downstream impacts of these injuries, research investigating injuries within law enforcement populations, although of fair quality, is limited [34]. A recent review by Lyons, et al. [34] found that the majority of studies in law enforcement contexts that have investigated injuries included only male participants. Understanding differences in injury presentations between male and female officers is of importance as research has shown that, for examples, male and female tactical personnel can suffer from different lower limb musculoskeletal injuries [35] and that lower limb interventions to address genderspecific injuries are effective [36]. Furthermore, the review found that there were no standard injury definitions, with many of the included studies failing to include any definition at all [34]. In addition, many of the included studies in the review only reported body site of injury in terms of broad locations, for example 'lower extremity' rather than a specific site such as the knee [34]. To address these gaps in the literature and to further inform future injury mitigation strategies, the aim of this retrospective cohort study was to profile lower extremity MSK injuries within a state police agency.

\section{Methods}

Retrospective injury data, collected by an Australian state police department as part of their standard operating procedures for recording workplace incidents and injuries, were provided to the research team for analysis. The data consisted of 7 years of non-identifiable workplace injury records compiled from mandated incident reporting forms which recorded all workplace injuries submitted between 1st July 2009 and 30th June 2016 with data input to the system by qualified and task dedicated personnel. Population data were also provided by this Australian state police department for the financial years $2009 / 2010-2015 / 2016$, to enable calculation of injury rates.

For this study, workplace injury was defined as 'harm to the body which occurred as a result of energy applied to the body whilst on duty'. This definition was derived 
from a previous literature review [34] of the injuries sustained by LEO and fitted to the reporting context of this population. MSK injuries were defined by the CDC definition provided above [1]. Lower extremity was defined to include toes, foot, ankle, knee, groin, hip, upper leg and lower leg. The pelvis was not included, in order to allow for comparison with findings from other tactical population research, which excluded the pelvis [37]. The data were refined in a manner that reflected these definitions, by employing a tiered exclusion process. First, injured body sites which did not meet the lower extremity criteria were removed, and this was followed by removal of records of non-MSK injuries. The data were then manually checked to ensure there were no ineligible entries remaining.

Ethics approval for the research was granted by the Bond University Human Research Ethics Committee (BUHREC) (Research Protocol 15360), with gatekeeper approvals also obtained from the police force from which the data were drawn.

Upon receiving the injury data, most of the data had already been systematically coded by the state police agency as part of their data entry procedure. For the data variables which were not coded (e.g. incident type), a predetermined numerical code was assigned in a systematic and standardised fashion (e.g. Male $=1$, Female $=2$ etc.), to allow for interpretation by the analysis software. The coding systems for these originally uncoded variables were generated by the researchers, with a code sheet created to ensure consistency in records categorisation. The coded data were then imported into IBM SPSS (version 24) [38] for analysis.

Statistical analysis of the data were initially completed descriptively, which enabled frequencies to be determined and means with standard deviations (SD) to be calculated for appropriate variables, such as lengths of shifts, hours worked 7 days prior to injury, and hours worked prior to incident occurrence. Chi-square tests of independence were then performed to compare frequencies from key descriptive variables between genders, with Cramer's V then calculated to determine the strength of any significant association with the alpha level set at $<.001$, a priori.
Shift lengths were divided into three categories - beginning, middle and closing third of shift - with a chi-square goodness of fit conducted to determine differences in proportions of injuries reported in each third of the shift. The alpha level was deliberately stringent to account for the large number of chi-square analyses conducted and to control family-wise error rates.

Incidence rates were calculated per annum using the following formula, where the total number of injuries and the annual population numbers used were either all, female only or male only, to determine the incidence rates for each. The total number of injuries and the sum of annual populations were each divided by seven because the data covered a seven-year period in each case and needed to be converted to average annual numbers.

$$
\begin{aligned}
\text { Annual MSK injury incidence } & =\frac{(\text { total number of injuries } \div 7)}{(\text { sum of annual population } \div 7)} \\
& \times 100 \text { injuries per } 100 \text { personnel }
\end{aligned}
$$

\section{Results}

Population sizes for LEO serving in the Australian state police department that was the focus of this study over the years included in this study are detailed in Table 1 , which includes a gender breakdown of the annual populations.

In total, 65,579 workplace injuries were reported. On implementation of the first data exclusion criterion, records $(n=48,959$ : $75 \%)$ which did not identify the lower extremity as the body site of injury were removed from the total data set, leaving 16,620 (25\%) records pertaining to lower extremity injuries. On implementation of the second data exclusion criterion, records $(n=4168$ : $6 \%$ ) of non MSK injuries were removed from this data set, leaving 12,452 (19\%) records pertaining to lower extremity MSK injuries; 9055 (72.7\%) involved male officers and 3397 (27.3\%) involved female officers. Therefore, the overall MSK lower extremity incidence rates were 10.8 injuries per 100 personnel/year overall, 10.8 injuries per 100 personnel/year for male LEO, and 11.0 injuries per 100 personnel/year for female LEO.

Table 1 Police department population sizes (sworn members), by financial year, from 1st July 2009 to 30 th June 2016

\begin{tabular}{llll}
\hline${ }^{2}$ Financial Year (FY) & Total LEO number & Male officer number (\%) & Female officer number (\%) \\
\hline FY09-10 & 16,112 & $11,814(73.3 \%)$ & $4298(26.7 \%)$ \\
FY10-11 & 16,033 & $11,746(73.3 \%)$ & $4287(26.7 \%)$ \\
FY11-12 & 16,293 & $11,918(73.1 \%)$ & $4375(26.9 \%)$ \\
FY12-13 & 16,384 & $11,962(73.0 \%)$ & $4422(27.0 \%)$ \\
FY13-14 & 16,692 & $12,151(72.8 \%)$ & $4541(27.2 \%)$ \\
FY14-15 & 16,659 & $12,106(72.7 \%)$ & $4553(27.3 \%)$ \\
FY15-16 & 16,677 & $12,132(72.7 \%)$ & $4545(27.3 \%)$ \\
\hline
\end{tabular}

${ }^{\mathrm{a}} \mathrm{FY}$ is defined as the period between 1 July of 1 year and 30 June of the next year 
Due to potential entry errors $99(0.8 \%)$ entries were removed, as shift lengths were reported as being longer than $13 \mathrm{~h}$ and thus considered by data providers to be a potential error, and a further 89 reports did not record shift length. Based on the remaining 12,264 records, the mean number of hours worked per shift prior to each reported injury was $6.00( \pm 3.56)$ hours with $36.5 \%$ occurring $<4.34 \mathrm{~h}, 37.5 \%$ between $4.34-8.67 \mathrm{~h}$ and $26.0 \%$ occurring between 8.68 and $13 \mathrm{~h}$. A significantly greater number of injuries occurred during the middle third of the shift $\left(X^{2}(2)=298.221, p<.001\right)$.

The top three injured body site categories were found to be the 'knee' $(n=3915,31 \%)$, 'multiple body sites including lower extremity' $(n=3794,30 \%)$, and the 'ankle' ( $n=1287,10 \%)$. The full injury body site distribution is shown in Fig. 1, with male and female officer comparisons also provided.

The most common nature of injury in the LEO was 'sprains/strains' $(n=5259,42 \%)$, followed by 'multiple natures including MSK' $(n=3614,29 \%)$ and 'bruises/ swelling' ( $n=3341,27 \%)$, with the least common being 'amputation/crushing' $(n=1)$. The proportions of injury by body site for each nature of injury is shown in Table 2 .

There was a statistically significant, albeit weak [39] association (Cramer's $\mathrm{V}=0.106$ ) between gender and the nature of injury $(\chi 2[6]=138.893, p<.001)$. The most common nature of injury, when comparing between genders, was found to be 'sprains/strains' for both male

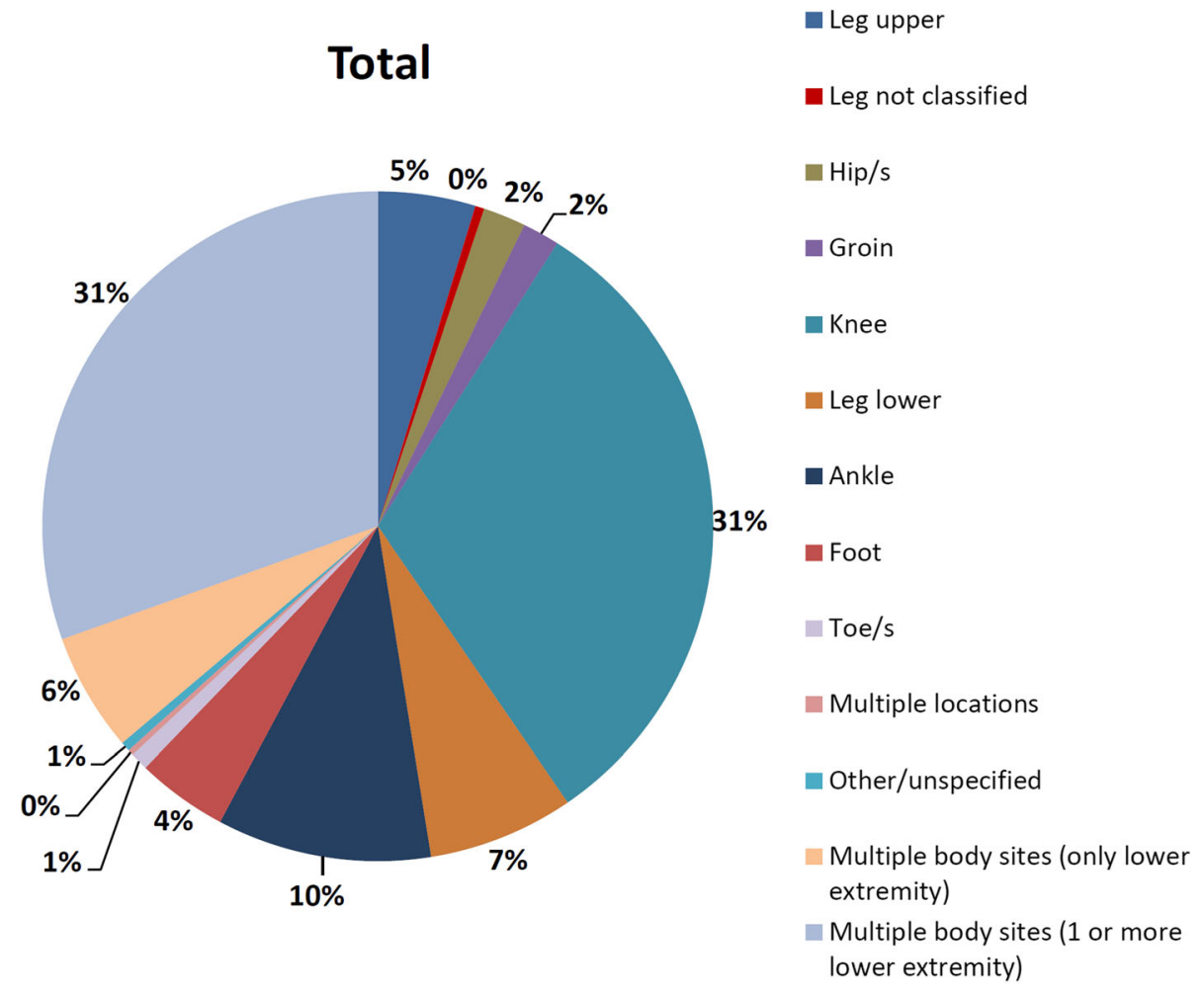

Male Officers

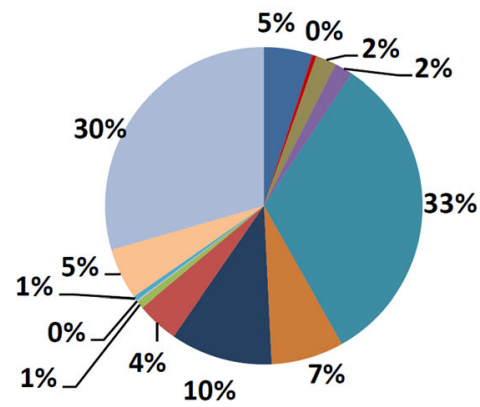

Female Officers

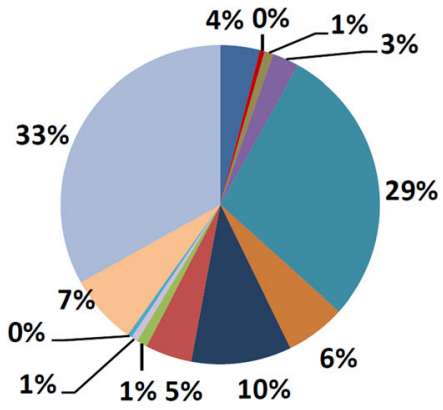

Fig. 1 Pie charts showing the distributions of injured body sites across all injured personnel (\%) and by gender 
Table 2 The proportions of injury by body site for each nature of injury

\begin{tabular}{|c|c|c|c|c|c|c|c|c|}
\hline $\begin{array}{l}\text { Nature of Injury } \\
\text { Body Site }\end{array}$ & $\begin{array}{l}\text { Sprains/ } \\
\text { Strains }\end{array}$ & $\begin{array}{l}\text { Multiple } \\
\text { Natures }\end{array}$ & $\begin{array}{l}\text { Bruises/ } \\
\text { Swelling }\end{array}$ & $\begin{array}{l}\text { Fractures/ } \\
\text { Dislocations }\end{array}$ & $\begin{array}{l}\text { Occupational } \\
\text { Overuse } \\
\text { Syndrome }\end{array}$ & Other & $\begin{array}{l}\text { Amputation/ } \\
\text { Crushing }\end{array}$ & Total \\
\hline Leg Upper & $62.2 \%$ & $8.0 \%$ & $29.2 \%$ & $0.5 \%$ & $<0.1 \%$ & $0.01 \%$ & $<0.1 \%$ & $100 \%$ \\
\hline Leg Not Classified & $35.7 \%$ & $17.8 \%$ & $41.1 \%$ & $5.4 \%$ & $<0.1 \%$ & $<0.1 \%$ & $<0.1 \%$ & $100 \%$ \\
\hline Hip & $59.0 \%$ & $5.5 \%$ & $30.8 \%$ & $1.2 \%$ & $3.5 \%$ & $<0.1 \%$ & $<0.1 \%$ & $100 \%$ \\
\hline Groin & $62.6 \%$ & $4.1 \%$ & $33.3 \%$ & $<0.1 \%$ & $<0.1 \%$ & $<0.1 \%$ & $<0.1 \%$ & $100 \%$ \\
\hline Knee & $50.3 \%$ & $15.7 \%$ & $32.7 \%$ & $1.2 \%$ & $0.1 \%$ & $<0.1 \%$ & $<0.1 \%$ & $100 \%$ \\
\hline Leg Lower & $45.3 \%$ & $18.5 \%$ & $32.3 \%$ & $3.8 \%$ & $0.1 \%$ & $<0.1 \%$ & $<0.1 \%$ & $100 \%$ \\
\hline Ankle & $62.7 \%$ & $8.9 \%$ & $25.7 \%$ & $2.6 \%$ & $0.1 \%$ & $<0.1 \%$ & $<0.1 \%$ & $100 \%$ \\
\hline Foot & $44.8 \%$ & $6.8 \%$ & $42.8 \%$ & $4.8 \%$ & $0.8 \%$ & $<0.1 \%$ & $<0.1 \%$ & $100 \%$ \\
\hline Toe/s & $12.0 \%$ & $12.0 \%$ & $59.3 \%$ & $14.8 \%$ & $0.9 \%$ & $0.10 \%$ & $0.9 \%$ & $100 \%$ \\
\hline Multiple Locations & $<0.1 \%$ & $5.7 \%$ & $91.4 \%$ & $2.9 \%$ & $<0.1 \%$ & $<0.1 \%$ & $<0.1 \%$ & $100 \%$ \\
\hline Other/ Unspecified & $<0.1 \%$ & $<0.1 \%$ & $75.4 \%$ & $21.1 \%$ & $3.5 \%$ & $<0.1 \%$ & $<0.1 \%$ & $100 \%$ \\
\hline Multiple body sites (Only MSK) & $36.6 \%$ & $42.4 \%$ & $20.2 \%$ & $0.7 \%$ & $0.1 \%$ & $<0.1 \%$ & $<0.1 \%$ & $100 \%$ \\
\hline Multiple body sites (including MSK) & $23.6 \%$ & $60.5 \%$ & $15.3 \%$ & $0.4 \%$ & $0.2 \%$ & $<0.1 \%$ & $<0.1 \%$ & $100 \%$ \\
\hline
\end{tabular}

officers $(n=4060,45 \%)$ and female officers $(n=1199$, $35 \%)$. This was followed by 'multiple natures including MSK' $(n=2626,29 \%)$ and 'bruises/swelling' $(n=2196$, $24 \%)$ for male officers and 'bruises/swelling' $(n=1145$, $34 \%)$ and 'multiple natures including MSK' $(n=988$, 29\%) for female officers.

When considering levels of reported injury severity, based on treatment received and lost work time, a substantial proportion of injuries were reported as 'notification only with no time loss or treatment' ( $n=8573,69 \%$; meaning the injury was reported only to document the injury and associated risk or hazard and that no medical treatment was required and no time was lost from work), and this was followed by 'medical treatment only - with no time loss' $(n=1921,15 \%)$, and 'medical treatment only - with time loss' ( $n=1484,12 \%)$. Only a small number of injuries required 'hospitalisation' $(n=429$, $3 \%)$ and the remaining injuries $(n=45,0.4 \%)$ were recorded as 'treatment not stated'. The levels of injury severity recorded for male and female officers did not differ significantly, as shown by a weak [39] association (Cramer's $\mathrm{V}=0.028$ ) between gender and injury severity categorisation $(\mathrm{X} 2[4]=10.033, p=.040)$. For both male $(n=6257,69 \%)$ and female officers $(n=2316,68 \%)$ 'notification only with no time loss or treatment' was the most common level of severity, followed by 'medical treatment only - with no time loss' (male officers: $n=$ 1408, 16\%; female officers: $n=513,15 \%$ ), and 'medical treatment only - with time loss' (male officers: $n=1039$, 12\%; female officers: $n=445,13 \%$ ).

The most common locations at which injuries occurred were reported to be 'at the workplace' (i.e., at the station/lab/office or in a police vehicle; $n=4656,37 \%$ ), 'at work but not on police premises' $(n=4544,37 \%)$, or 'on patrol' $(n=1915,15 \%)$. The smallest numbers of injuries were reported to occur 'at a crime scene' $(n=590$, $5 \%)$. There was a statistically significant, albeit weak [39] association (Cramer's $\mathrm{V}=0.137$ ) between gender and the locations at which injuries occurred $(\chi 2[4]=232.195$, $p<.001)$. For male officers being 'at work but not on police premises' $(n=3438,38 \%)$, 'at the workplace', $(n=$ $3178,35 \%)$, and 'on patrol' $(n=1556,17 \%)$ were the most common locations at which injuries occurred. Conversely, for female officers the most common locations at which injuries occurred were 'at the workplace' ( $n=1478,44 \%)$, 'at work but not on police premises' ( $n=1106,33 \%)$, and 'on patrol' $(n=359,11 \%)$.

'Arresting offenders' ( $n=3012,24 \%)$ was found to be the most common activity being undertaken at the time an injury occurred, followed by 'walking/running' ( $n=$ 1446, 12\%) and 'other/unspecified' activities $(n=1139$, 9\%). 'Motorcycle pursuits' and 'parking control' were found to be the least common activities, associated with only three injuries in total $(<0.1 \%)$. When comparing between genders, there was a statistically significant, albeit weak [39] association (Cramer's $V=0.236$ ) between gender and the activity being undertaken at the time of injury $(x 2[35]=692.201, p<.001)$. The most common activity being performed at the time an injury occurred was 'arresting an offender' ( $n=2450,27 \%)$, followed by 'walking/running' $(n=838,9 \%)$, and 'foot pursuit' $(n=$ 837, 9\%) for male officers and 'walking/running' ( $n=$ $608,18 \%)$, followed by 'arresting an offender' $(n=562$, $17 \%)$, and 'general duties' $(n=382,11 \%)$ for female officers.

'Slips/trips/falls' ( $n=4701,38 \%)$, and 'physical assault' ( $n=1839,15 \%)$ were found to be the top two causes of injuries, followed by 'other/unspecified' causes $(n=1427$, 
$12 \%)$. In relation to gender differences in percentages of injuries associated with slips, trips and falls, particularly, there was a statistically significant, albeit weak [39] association (Cramer's $\mathrm{V}=0.137$ ) between gender and the cause of the incident $(x 2[32]=253.134, p<.001)$. The most common cause of injury for both male officers $(n=3204,35 \%)$ and female officers $(n=1497,44 \%)$ was 'slips/trips/falls' with little difference in the two following most common causes of injury, being 'physical assault' (male officers: $n=1369,15 \%$; female officers: $n=470$, 14\%), and 'other/unspecified' (male officers: $n=970$, $11 \%$; female officers: $n=457,12 \%$ ). These results suggest that female officers were more likely than male officers to incur an injury due to slips, trips and falls.

The most common duty types being undertaken by officers at the time of injury were found to be 'general duties' ( $n=5924,48 \%)$, 'highway patrol' $(n=1318,11 \%)$, and 'criminal investigator' $(n=926,7 \%)$. When comparing between genders, the most common duty type for both genders was 'general duties' (male officers: $n=$ 4339, 48\%; female officers: $n=1585,47 \%$ ), followed by 'highway patrol' (male officers: $n=909,10 \%$; female officers: $n=409,12 \%$ ), and 'criminal investigator' (male officers: $n=693,8 \%$; female officers: $n=233,7 \%$ ). However, while the most common types of duties being undertaken at the time of injury were very similar for male and female officers, their was a weak [39] association (Cramer's V $=0.090$ ) between gender and the duty type at time of injury $(x 2[37]=101.385, p<.001)$. These differences arose from variations in other duty types between the genders. For example, for female officers, 2.4\% $(n=81)$ of injuries arose from water policing duties, while a lower $1.6 \%(n=143)$ occurred for male officers completing these same duties.

\section{Discussion}

The aim of this retrospective cohort study was to profile lower extremity MSK injuries within a state police agency. Lower extremity MSK injuries accounted for $19 \%$ of all reported work health and safety incidents. The overall MSK lower extremity incidence rates were 10.8 injuries per 100 personnel/year overall, 10.8 per $100 \mathrm{personnel/year} \mathrm{for}$ male LEO and 11.0 per 100 personnel/year for female LEO. The 'knee' was the body site of $31 \%$, and 'sprains/ strains' were the nature of injury for over $42 \%$. For $69 \%$ of the reported lower extremity MSK injuries, the level of severity was reported as 'notification only with no time loss or treatment', and 'the workplace' was the most common location where the injuries were reported to occur (37\%). 'Arresting offenders' was the most common activity being undertaken at the time injuries occurred (24\%), 'slips/ trips/falls' caused $38 \%$ of the reported injuries, and $48 \%$ of the injuries were reported to have occurred during the performance of 'general duties'.
Similar to the findings of this study, other studies of LEO injuries by Sullivan and Shimizu [18] and Holloway-Beth et al. [40] found lower extremity injuries represented 13 and $30 \%$ of all reported workplace health and safety incidents, respectively. In the first study by Sullivan and Shimizu [18] 2167 descriptive injury claims, 417 retrospective worker's compensation claims and 261 prospective claims were investigated from the Los Angeles county sheriff's department. Similar to the current study, the retrospective data in that study showed the top site of lower limb injury to be the knee. The study of Holloway-Beth et al. was also completed in a law enforcement population, however the 18,892 claims in that study included claims from personnel of correctional institutions, municipal police, sheriff's department personnel and state police. The differences in law enforcement populations, together with differences in definitions of incidents and injuries may account for the differences in proportions of incidents that were reported as lower extremity injuries across these three studies.

In other tactical populations, such as fire and rescue and the military, the lower extremity has been reported to be the body site affected in a larger proportion of incidents than in LEO. In fire and rescue populations the lower extremity is affected in $32 \%$ [7] to $37 \%$ [8] of reported injuries. In military populations, the lower extremity has also been reported to be the site of injury in a larger proportion of overall injuries [22] varying from $31.7 \%$ [6] to $82 \%$ [41] depending on the military population. Within U.S. Marine Corps training, injuries to the lower extremity can comprise up to $82 \%$ [41] of reported injuries. Other military populations such as U.S. Army male infantry trainees, Norwegian conscripts, U.S. Military non-deployed active duty personnel, Australian Defence Force personnel undertaking physical training and the overall Australian Defence Force population have reported the lower extremity to be affected in $80 \%$ [20], 63\% [42], 39\% [43], 48\% [6], and $31.7 \%$ [6] of incidents, respectively.

In the aforementioned fire and rescue and military studies, it was not stated whether the lower extremity injuries reported were specifically MSK injuries and this may have contributed to the higher proportions of injuries involving the lower extremity when compared to the law enforcement population considered in the current study. Another contributing factor to this variation between studies in different tactical populations may be differences in occupational tasks, such as load carriage requirements, which can contribute to an increased injury risk $[6,9,20-23]$. LEO carry loads which can range from $3 \mathrm{~kg}$ to $15 \mathrm{~kg}$ [26] in general duties officers, normally consisting of duty belts and associated appointments, but they can also include body armour or additional equipment 
[23, 44, 45]. In specialist officers this can increase to loads of between $22 \mathrm{~kg}$ [27] and $40 \mathrm{~kg}$ [28], consisting of duty belts, body armour, specialist weapons, breaching equipment, ballistic shields and various personal protective equipment [23, 27, 28, 44-48]. Fire and rescue populations can carry loads ranging from $16 \mathrm{~kg}$ to $22 \mathrm{~kg}[49,50]$. Within the military, load carriage is often heavier than in the other two tactical populations, reaching $45 \mathrm{~kg}$ or more $[49,51]$.

In military populations, the most common lower extremity injuries have been reported to be the ankle, with percentages varying from $13 \%$ [43] to $37 \%$ [9], and the knee, which is affected in between $22 \%[9,43]$ and $35 \%$ [22] of all lower extremity injuries. However, underreporting of injuries within the military is common and the knee is the most frequently under-reported area, representing $20 \%$ of all unreported injuries [52]. Another recent study [53] also reported there to be a very high likelihood of substantial under-reporting (estimated at $80-90 \%$ of injuries unreported) on work health and safety incident reporting systems within military populations. Within the fire and rescue population the knee is the most common body site of injury, and it has been found to be affected in between 10\% [54] and 14\% [7] of all injuries, and in 45\% [54] of lower extremity injuries. Accounting for the under-reporting within the military population, fire and rescue and military personnel appear to exhibit a relatively greater number of knee injuries than LEO. Reasons for this difference may include differing occupational tasks [31] - particularly load carriage requirements, which have been reported to cause knee injuries within military populations [55-58]. Greater load carriage demands in both military $[49,51]$, and fire and rescue $[49,50]$ personnel may increase the incidence of lower extremity injuries [6, 9, 20-23], particularly of the knee [55-58], in these populations.

The most common nature of injury was found in the current study to be sprains and strains (42.3\%). Similarly a critical review of studies investigating law enforcement injuries by Lyons et al. [34], found that the most common nature of injury was also sprains/strains, varying from $42 \%$ [14] to $95 \%$ of reported injuries [16]. In the military population, sprains/strains have also been found to be the most common nature of injury, accounting for $80 \%$ of injuries [9]. Similarly, in the fire and rescue population sprains/strains were the most common types of injury, accounting for between 40 and $85 \%$ [8, 59-61] of all injuries. This is also the case in sporting populations such as athletes from weight-lifting sports [62], high school sports [63], ballet [64], and track and field [65].

The reported level of severity for the majority of lower limb MSK injuries (69\%) in this study was "notification only with no time loss or treatment". This was followed by "medical treatment only with no time lost" (15\%). In total, $84 \%$ of all lower extremity MSK injuries resulted in "no time lost". In the aforementioned critical review [34] of the literature focusing on the law enforcement population, sixteen articles [12-18, 40, 66-73] were included and in these studies treatment types and time loss, as indicators of severity, were not specifically reported. In the military study discussed [74], treatment was not reported whereas severity of injury was, with 'minor injuries' comprising approximately $57 \%$ of injuries, which is lower than the proportion of law enforcement injuries reported in the current study that involved 'no time loss or treatment' and so also could be considered 'minor'. In the fire and rescue population, similar statistics to those for law enforcement were found - injuries were, where relevant, classified as minor, which was described as notification only, first aid only or medical treatment without time lost, representing 68\% [54] to $96 \%$ of injuries [8]. The results of this study and from fire and rescue populations [54] suggest that the majority of incidents in these two populations were of a minor severity and involved no time lost, whereas in the military this proportion was substantially less although the minor injury contribution still represented over one half of injuries. These differences between populations may be attributed to deployed environments and combat related injuries causing higher severities of injuries within the military population as well as the aforementioned underreporting in military contexts, which may be more likely with minor injuries.

The most common locations at which injuries occurred were reported to be at the workplace (37\%) and at work but not on police premises (37\%). With no other LEO studies reporting the locations at which injuries occurred, comparisons were limited to military and fire-fighter populations. In contrast to the findings of this study, the military population attributed the majority of injuries to playing individual or team sport (64\%), followed by completing physical training (20\%) [9], both of which may, or may not, have occurred at the workplace. Similar to law enforcement in the fire and rescue population, 59\% of injuries occurred at a fire station, whilst 36\% occurred whilst at work but not within the station itself, and $4 \%$ were attributed to work related travel [7]. When comparing this particular element of injury profiling it is important to note that in the military, physical training may have been mandatory and as many members participate in physical training and sports as part of their military duties, this workplace requirement may account for the variation in the locations at which injuries occur when compared to other tactical populations.

Arresting offenders (24\%) was found to be the most common activity being undertaken by LEO at the time they were injured, followed by walking/running (12\%). In contrast to this study, a study by Larsen et al. [16] in a LEO population found that over half of the injuries reported in their study occurred during police specific 
occupational tasks, whilst greater than $30 \%$ occurred during training. Differences between the common activities associated with injuries in these studies, which both used data from state LEO in Australia, may be due to the current study reporting only on MSK lower extremity injuries for all officers, and the other study reporting only on a specialist unit and on all injuries. In the military population it has been reported that most injuries occur within military training $[6,9,21,22,41-43,53]$, although one study reported $33 \%$ of injuries occurred whilst walking/jogging [9]. Within the fire and rescue population two studies $[60,75]$ found that the most common activity at the time of injury was training/physical exercise (including walking/running), which in one study accounted for $33.3 \%$ of injuries [60]. In contrast, another study [59] reported the most common activity at time of injury to be fire and rescue specific occupational demands. However, over $30 \%$ of reported injuries in this study were still attributed to physical training [59]. Differences in activities associated with injuries relate directly to the types of occupational tasks. Arresting offenders is predominantly a law enforcement specific task and therefore is unlikely to be seen in other tactical populations to a great extent (e.g it might be seen in military police) if at all. Interestingly, physical exercise/ training, which likely involves walking/running, appears in the top two activity types associated with injuries across all three tactical populations.

Slips/trips/falls (37.8\%) and physical assault (14.8\%) were found to be the top two causes of lower extremity MSK injuries for this state law enforcement population. Within military populations, the most common cause of lower limb injuries is over-exertion, both acute overexertion and cumulative loading, which account for 59\% of injuries, with slips/trips/falls causing 19\% [9]. In fire and rescue populations, muscular stress both without external load and with an external load accounted for 29.7\% of injuries, while slips/trips/falls accounted for $15.1 \%$ of injuries [7]. Slips/trips/falls contribute to a larger proportion of injuries within LEO when compared to military and fire and rescue populations. Reasons for this may be increased load carriage demands in the other two occupations, causing muscular stress/exertional injuries [21, 76].

The most common duty type in which injuries occurred in the LEO was general duties (47.6\%), followed by highway patrol (10.6\%). These duty types are specific to the law enforcement occupation and are therefore unable to be compared with other tactical populations. Likewise, the nature of law enforcement work produced some interesting results in relation to when injuries occurred during a shift. Significantly more injuries occurred during the middle third of the shift, although the actual differences in injuries reported between early and mid-shift was approximately $1 \% \quad(n=116$ fewer injuries in the early third of the shift). A potential reason for this difference may be the administration associated with the ending of a shift (e.g. Hand over / Take over briefings) and hence the lower percentage of injuries reported (26\%) in the last third of a shift but further research is needed to support this supposition.

Differences between the genders did exist in several areas notably in location (i.e., in the workplace) and activity being performed (i.e., walking/running). In addition, female officers may be at a higher risk of slips, trips and falls. As such targeted injury prevention strategies may have different impacts between genders. For example, strategies to minimise injuries caused by 'physical assault' could reduce the incidence of these injuries equally for both female and male officers (currently 14 and $15 \%$ respectively). However, strategies to mitigate the risk of injury due to 'slips, trips and falls' may reduce the incidence of injuries to female officers to a greater extent than male officers (currently 44 and 35\% respectively). Of note, no differences in the severity of injuries between the genders were reported. This contrasts the findings of Orr et al. [35], who found that while male and female soldiers suffered similar levels of injuries due to occupational load carriage, female personnel were 2.4 times more likely to suffer a 'serious personal injury' than male personnel. Noting that the research by Orr et al. [35], was of a single task (load carriage) in a military population, potential differences in severity are reported by Hua et al. [77], who found that female police officers, in general, attended a greater number of inhouse physiotherapy treatments than male officers $(8.25 \pm 5.12$ vs. $6.57 \pm 4.03$ treatments respectively). Differences in these findings may be explained by several factors including, a lack of detail in regard to rating the severity of the injuries entered into the database, differences in reporting processes (e.g., self-reported, as was the case in this study) versus point-of-care (i.e. those attending physiotherapy treatment) [36].

The limitations to this study included; 1 ) that the classification systems employed in the original data were not very detailed, limiting information that could be derived from the dataset to guide injury prevention, 2) that the study focused on lower limb MSK injuries - other injury and incident types were outside the scope of the study.

The study also has several strengths. The data available were extensive, spanning 7 years and thousands of injury records. This study employed a standardised injury definition, which will enable future comparison across other tactical populations, where previously multiple different definitions have been used or no definition was provided. Finally, this study reports on a wide variety of key injury variables, including nature of injury, type of treatment, location at time of injury, activity at time of injury, cause of injury and the duty type, and the injured body site. 


\section{Conclusion}

Establishing the current profile of lower extremity injuries within a state law enforcement agency will address some of the current key limitations in the literature and enable ease of comparison to other occupations, government agencies and other tactical populations. This study found differences between LEO and other tactical populations in their profiles of lower extremity injuries, which may be due to the unique challenges LEOs face in their occupation, for example, arresting offenders, which was the most common activity being undertaken at time of injury. The most common site of lower extremity injury was found to be the 'knee', the most common nature 'sprains/strains', and the most common location of where the injury occurred was 'at the workplace' and 'at work but not on police premises'. These findings can be used to inform the future development of injury prevention protocols, resilience testing and current physical testing protocols.

\section{Abbreviations}

MSK: Musculoskeletal; CDC: Centre for Disease Control and Prevention; LEO: Law enforcement officers; BUHREC: Bond University Human Research Ethics Committee; SD: Standard deviations

\section{Acknowledgements}

The authors would like to acknowledge the personnel from the police agency that informed this study.

\section{Authors' contributions}

$\mathrm{KL}$ completed the background research, data coding and analysis and developed the manuscript. $\mathrm{RO}, \mathrm{MS}, \mathrm{BH}$, and RP all contributed to gaining ethics and departmental approvals for the research and reviewed the manuscript. MS and $\mathrm{BH}$ gathered the data. $\mathrm{RO}$ and $\mathrm{RP}$ confirmed the results and supervised the project. All authors read and approved the final manuscript.

\section{Funding}

The authors declare that there was no funding associated with this data.

\section{Availability of data and materials}

The data that support the findings of this study are not openly available given security restrictions within the police agency from which this data is drawn. However, researchers can apply for access to this data, and on meeting all ethics requirements bound by this research, a reach forward request to the police agency to release the data can be made.

\section{Ethics approval and consent to participate}

Ethics approval was granted by Bond University Human Research Ethics Committee (Research Protocol 15360). Consent to release this article was provided by the State Police department where this research took place.

\section{Consent for publication}

Not Applicable.

\section{Competing interests}

The authors declare that they have no competing interests.

\section{Author details}

${ }^{1}$ Bond Institute of Health and Sport, Bond University, Gold Coast, QLD 4229 Australia. ${ }^{2}$ NSW Police Force Reconditioning Program, Surry Hills, NSW 2010, Australia. ${ }^{3}$ Tactical Research Unit, Bond University, Gold Coast, QLD 4229, Australia. ${ }^{4}$ School of Community Health, Charles Sturt University, Albury, NSW 2640, Australia.
Received: 19 June 2020 Accepted: 19 January 2021

Published online: 26 January 2021

\section{References}

1. CDC. Musculoskeletal health program Atlanta, USA: Centres for disease control and prevention; 2016. Available from: https://www.cdc.gov/niosh/ programs/msd/

2. Hootman JM, Macera CA, Ainsworth BE, Martin M, Addy CL, Blair SN. Association among physical activity level, cardiorespiratory fitness, and risk of musculoskeletal injury. Am J Epidemiol. 2001;154(3):251-8.

3. Beattie PF, Nelson RM, Basile K. Differences among health care settings in utilization and type of physical rehabilitation administered to patients receiving workers' compensation for musculoskeletal disorders. J Occup Rehabil. 2013;23(3):347-60.

4. Lysaght $\mathrm{R}$, Donnelly $\mathrm{C}$, Luong $\mathrm{D}$. Best practices in the rehabilitation of acute musculoskeletal disorders in workers with injuries: an integrative review and analysis of evolving trends. Work (Reading, Mass). 2010;35(3):319-33.

5. Andersen JH, Haahr JP, Frost P. Risk factors for more severe regional musculoskeletal symptoms: a two-year prospective study of a general working population. Arthritis Rheum. 2007;56(4):1355-64.

6. Andersen KA, Grimshaw PN, Kelso RM, Bentley DJ. Musculoskeletal lower limb injury risk in Army populations. Sports Med Open. 2016;2:22.

7. Taylor NAS, Dodd MJ, Taylor EA, Donohoe AM. A retrospective evaluation of injuries to Australian urban firefighters (2003 to 2012): injury types, locations, and causal mechanisms. J Occup Environ Med. 2015;57(7):757-64.

8. Poplin GS, Harris RB, Pollack KM, Peate WF, Burgess JL. Beyond the fireground: injuries in the fire service. Injury Prev. 2011;18(4):228.

9. Davidson PL, Chalmers DJ, Wilson BD, McBride D. Lower limb injuries in New Zealand Defence force personnel: descriptive epidemiology. Aust N Z J Public Health. 2008;32(2):167-73.

10. Ferguson P, Prenzler T, Sarre R, De Caires B. Police and security officer experiences of occupational violence and injury in Australia. Int J Police Sci Manag. 2011;13(3):223-33.

11. Office of the Commissioner. NSW police force 2018-19 annual report. Sydney: New South Wales Police Force; 2019.

12. Boyce RW, Hiatt AR, Jones GR. Workers' compensation claims and physical fitness capacity of police officers. Health Values. 1992;16(4):22-9.

13. Brandl SG, Stroshine MS. Toward an understanding of the physical hazards of police work. Police Q. 2003;6(2):172-91.

14. Brandl SG, Stroshine MS. The physical hazards of police work revisited. Police Q. 2012;15(3):262-82.

15. Gyi DE, Porter JM. Musculoskeletal problems and driving in police officers. Occup Med (Oxford, England). 1998;48(3):153-60.

16. Larsen B, Aisbett B, Silk A. The injury profile of an Australian specialist policing unit. Int J Environ Res Public Health. 2016;13(4):370.

17. Nabeel I, Baker BA, McGrail MP Jr, Flottemesch TJ. Correlation between physical activity, fitness, and musculoskeletal injuries in police officers. Minn Med. 2007;90(9):40-3.

18. Sullivan CSB, Shimizu KT. Epidemiological studies of work-related injuries among law enforcement personnel. J Soc Occup Med. 1988;38(1-2):33-40.

19. Fekedulegn D, Burchfiel CM, Ma CC, Andrew ME, Hartley TA, Charles LE, et al. Fatigue and on-duty injury among police officers: the BCOPS study. J Saf Res. 2017;60:43-51.

20. Jones BH, Cowan DN, Tomlinson JP, Robinson JR, Polly DW, Frykman PN. Epidemiology of injuries associated with physical training among young men in the army. Army Res Inst Of Environ Med Natick Ma. 1993;25(2):197.

21. Orr RM, Johnston V, Coyle J, Pope R. Reported load carriage injuries of the Australian army soldier. J Occup Rehabil. 2015;25(2):316-22.

22. Orr RM, Pope R, Johnston V, Coyle J. Soldier occupational load carriage: a narrative review of associated injuries. Int J Inj Control Saf Promot. 2014; 21(4):388-96

23. Robinson J, Roberts A, Irving S, Orr R. Aerobic fitness is of greater importance than strength and power in the load carriage performance of specialist police. Int J Exerc Sci. 2018;11(4):987-98.

24. Ramstrand N, Zügner R, Larsen LB, Tranberg R. Evaluation of load carriage systems used by active duty police officers: relative effects on walking patterns and perceived comfort. Appl Ergon. 2016;53:36-43.

25. Baran K, Dulla J, Orr R, Dawes J, Pope R. Duty loads carried by the LA sheriff's department deputies. J Australian Strength Cond. 2018;26(5):34-8.

26. Dempsey PC, Handcock PJ, Rehrer NJ. Body Armour: the effect of load, exercise and distraction on landing forces. J Sports Sci. 2014;32(4):301-6. 
27. Carlton SD, Carbone PD, Stierli M, Orr R. The impact of occupational load carriage on the mobility of the tactical police officer. J Australian Strength Cond. 2014;15(1):88.

28. Pryor RR, Colburn D, Crill MT, Hostler DP, Suyama J. Fitness characteristics of a suburban special weapons and tactics team. J Strength Cond Res. 2012; 26(3):752-7.

29. Achterstraat P. Managing injured police: NSW police forceln: AuditorGeneral, editor. Sydney; 2008

30. Bonneau J, Brown J. Physical ability, fitness and police work. J Clin Forensic Med. 1995;2(3):157-64.

31. Rommel A, Varnaccia G, Lahmann N, Kottner J, Kroll LE. Occupational injuries in Germany: population-wide national survey data emphasize the importance of work-related factors. PLoS One. 2016;11(2):e0148798.

32. Ng YG, Tamrin SBM, Yik WM, Yusoff ISM, Mori I. The prevalence of musculoskeletal disorder and association with productivity loss: a preliminary study among labour intensive manual harvesting activities in oil palm plantation. Ind Health. 2014;52(1):78-85.

33. Bhattacharya A. Costs of occupational musculoskeletal disorders (MSDs) in the United States. Int J Ind Ergon. 2014:44(3):448-54

34. Lyons K, Radburn C, Orr R, Pope R. A profile of injuries sustained by law enforcement officers: a critical review. Int J Environ Res Public Health. 2017;14:2.

35. Orr RM, Pope R. Gender differences in load carriage injuries of Australian army soldiers. BMC Musculoskelet Disord. 2016;17(1):488.

36. Pope RP. Prevention of pelvic stress fractures in female army recruits. Mil Med. 1999;164(5):370-3.

37. Hruby A, Bulathsinhala L, McKinnon CJ, Hill OT, Montain SJ, Young AJ, et al. BMI and lower extremity injury in U.S. Army soldiers, 2001-2011. Am J Prev Med. 2016;50(6):e163-e71.

38. IBM. SPSS statistics. 24th ed; 2016

39. Cohen J. Statistical power analysis for the behavioral sciences: Taylor \& Francis; 1988.

40. Holloway-Beth A, Forst L, Freels S, Brandt-Rauf S, Friedman L. Occupational injury surveillance among law enforcement officers using workers' compensation data, Illinois 1980 to 2008. J Occup Environ Med. 2016;58(6): 594-600.

41. Almeida SA, Williams KM, Shaffer RA, Brodine SK. Epidemiological patterns of musculoskeletal injuries and physical training. Med Sci Sports Exerc. 1999; 31(8):1176-82.

42. Heir T, Glomsaker P. Epidemiology of musculoskeletal injuries among Norwegian conscripts undergoing basic military training. Scand J Med Sci Sports. 1996;6(3):186-91.

43. Hauret KG, Jones BH, Bullock SH, Canham-Chervak M, Canada S Musculoskeletal injuries description of an under-recognized injury problem among military personnel. Am J Prev Med. 2009;38(1):S61-70.

44. Blacker SD, Carter JM, Wilkinson DM, Richmond VL, Rayson MP, Peattie M. Physiological responses of police officers during job simulations wearing chemical, biological, radiological and nuclear personal protective equipment. Ergonomics. 2013;56(1):137-47.

45. DiVencenzo HR, Morgan AL, Laurent CM, Keylock KT. Metabolic demands of law enforcement personal protective equipment during exercise tasks. Ergonomics. 2014;57(11):1760-5.

46. Dempsey PC, Handcock PJ, Rehrer NJ. Impact of police body Armour and equipment on mobility. Appl Ergon. 2013:44(6):957-61.

47. Larsen B, Netto K, Skovli D, Vincs K, Vu S, Aisbett B. Body armor, performance, and physiology during repeated high-intensity work tasks. Mil Med. 2012;177(11):1308-15

48. Lewinski WJ, Dysterheft JL, Dicks ND, Pettitt RW. The influence of officer equipment and protection on short sprinting performance. Appl Ergon. 2015:47:65-71.

49. Joseph A, Wiley A, Orr R, Schram B, Dawes JJ. The impact of load carriage on measures of power and agility in tactical occupations: a critical review. Int J Environ Res Public Health. 2018;15:1.

50. Leadbetter GW, Ruby BC, Armstrong D. Wildland firefighter load carriage. Med Sci Sports Exerc. 2001;33(5):S99.

51. Orr R. The history of the soldier's load. Aust Army J. 2010;7(2):67.

52. Smith L, Westrick R, Sauers S, Cooper A, Scofield D, Claro P, et al. Underreporting of musculoskeletal injuries in the US Army: findings from an infantry brigade combat team survey study. Sports Health. 2016;8(6):507-13.

53. Pope R, Orr R. Incidence rates for work health and safety incidents and injuries in Australian Army reserve vs full time soldiers, and a comparison of reporting systems. J Military Veteran's Health. 2017;25(2):16-25.
54. Campbell R. Patterns of firefighter Fireground injuriesAssociation NFP, editor. Quincy: MA 02169 NFPA Research; 2016.

55. Orr RM, Pope R, Coyle J, Johnston V. Occupational loads carried by Australian soldiers on military operations. J Health Saf Environ. 2015;31(1): 451-67.

56. Orr RM, Pope RR. Load carriage: an integrated risk management approach. J Strength Cond Res. 2015;29(Suppl 11):S119-28.

57. Knapik J, Reynolds K, Staab J, Vogel JA, Jones B. Injuries associated with strenuous road marching. Mil Med. 1992:157(2):64-7.

58. Knapik J, Johnson R, Ang P, Meiselman H, Bensel C. Road march performance of special operations soldiers carrying various loads and load distributions. DTIC document; 1993

59. Frost DM, Beach TA, Crosby I, McGill SM. The cost and distribution of firefighter injuries in a large Canadian fire department. Work (Reading, Mass). 2016:55(3):497-504.

60. Jahnke SA, Poston WSC, Haddock CK, Jitnarin N. Injury among a population based sample of career firefighters in the Central USA. Injury Prev. 2013. 19(6):393-8.

61. Frost DM, Beach TA, Crosby I, McGill SM. Firefighter injuries are not just a fireground problem. Work (Reading, Mass). 2015;52(4):835-42.

62. Keogh JW, Winwood PW. The epidemiology of injuries across the weighttraining sports. Sports Med (Auckland, NZ). 2017:47(3):479-501.

63. Patel DR, Yamasaki A, Brown K. Epidemiology of sports-related musculoskeletal injuries in young athletes in United States. Transl Pediatr. 2017;6(3):160

64. Caine D, Goodwin BJ, Caine CG, Bergeron G. Epidemiological review of injury in pre-professional ballet dancers. J Dance Med Sci. 2015; 19(4):140-8.

65. Jacobsson J, Timpka T, Kowalski J, Nilsson S, Ekberg J, Renström P. Prevalence of musculoskeletal injuries in Swedish elite track and field athletes. Am J Sports Med. 2012:40(1):163-9.

66. Rhee HY, Cho JH, Seok JM, Cho TS, Jeon WJ, Lee JG, et al. Prevalence of musculoskeletal disorders among Korean police personnel. Arch Environ Occup Health. 2015;70(4):177-88

67. Cho T-S, Jeon W-J, Lee J-G, Seok J-M, Cho J-H. Factors affecting the musculoskeletal symptoms of Korean police officers. J Phys Ther Sci. 2014 26(6):925-30.

68. Violanti JM, Fekedulegn D, Andrew ME, Charles LE, Hartley TA, Vila B, et al. Shift work and long-term injury among police officers. Scand J Work Environ Health. 2013;39(4):361-8.

69. Knapik JJ, Grier T, Spiess A, Swedler DI, Hauret KG, Graham B, et al. Injury rates and injury risk factors among federal bureau of investigation new agent trainees. BMC Public Health. 2011;11(1):1-16.

70. Reichard AA, Jackson LL. Occupational injuries among emergency responders. Am J Ind Med. 2010;53(1):1-11.

71. Jahani MR, Motevalian SA, Asgari AR. Musculoskeletal disabilities among police force personnel of the Islamic Republic of Iran. Mil Med. 2002;167(10): $850-2$.

72. Burton AK, Tillotson KM, Symonds TL, Burke C, Mathewson T. Occupational risk factors for the first-onset and subsequent course of low back trouble: a study of serving police officers. Spine (03622436). 1996;21(22):2612-20.

73. Superko HR, Bernauer E, Voss J. Effects of a mandatory health screening and physical maintenance program for law enforcement officers. Phys Sportsmed. 1988:16(9):99-109.

74. Glad D, Skillgate E, Holm LW. The occurrence and severity of musculoskeletal disorders in Swedish military personnel during peacekeeping operations in Afghanistan. Eur Spine J. 2012;21(4):739-44.

75. Szubert Z, Sobala W. Work-related injuries among firefighters: sites and circumstances of their occurrence. Int J Occup Med Environ Health. 2002; 15(1):49-55.

76. Hauschild V, Roy T, Grier T, Schuh A, Jones BH. Foot marching, load carriage, and injury risk: Army Public Health Center Aberdeen Proving GroundEdgewood Area United States; 2016.

77. Hua M, Orr RM, Stierli M. Profiling a workplace physiotherapy and rehabilitation program within a police force. Gold Coast: CONNECT 2015 Physiotherapy Conference; 2015.

\section{Publisher's Note}

Springer Nature remains neutral with regard to jurisdictional claims in published maps and institutional affiliations. 